125993, г. Москва, Волоколамское шоссе, 4. Тел.: (499) 158-29-77.

Ключевые слова: электронный поток; мощность СВЧ; группирователь; повторное магнит- ное поле; клистронный метод; релятивистский электрон; поперечное магнитное поле; электронные сгустки.

\title{
EVALUATION OF THE MICROWAVE POWER OF A BUNCHER IN A REPEATED MAGNETIC FIELD
}

Kuzmin Konstantin Anatolyevich, Candidate of Pedagogical Sciences, Associate Professor of the chair "Science and Technical Disciplines and Information Technology", K.G. Razumovsky Moscow State University of Technologies and Management (the First Cossack University), Russia.

Morozov Sergey Mikhaylovich, Candidate of Technical Sciences, Associate Professor, Head of the chair "Science and Technical Disciplines and Information Technology", K.G. Razumovsky Moscow State University of Technologies and Management (the First Cossack University), Russia.

Pavlov Igor Valentinovich, Candidate of Pedagogical Sciences, Associate Professor of the chair "Science and Technical Disciplines and Information Technology", K.G. Razumovsky Moscow State University of Technologies and Management (the First Cossack University), Russia.

Reut Vladimir Antonovich, Candidate of Pedagogical Sciences, Associate Professor of the chair "Science and Technical Disciplines and Information Technology", K.G. Razumovsky
Moscow State University of Technologies and Management (the First Cossack University), Russia.

Balmashnova Elena Vitalyevna, Teacher of the chair "Technology and Organization of Construction Production", National Research Moscow State University of Civil Engineering. Russia.

Morozov Mikhail Sergeevich, Leading Engineer, Moscow Aviation Institute. Russia.

Keywords: electronic stream; microwave power; buncher; repeated magnetic field; klystron method; relativistic electron; transverse magnetic field; electronic clots.

The article considers the klystron method of grouping in a repeated magnetic field. In the long-wavelength range, in addition to gyrocon and magnicon, microwave tetrodes and multi-cavity klystrons are used. Conventional klystrons in the decimeter range have significant dimensions, and their application becomes problematic, and microwave tetrodes have a significant power level, but low efficiency and gain ratio.

\section{ПРОБЛЕМЫ СОХРАНЕНИЯ СЕНАЖА В РУЛОНЕ, УПАКОВАННОГО В ПЛЕНКУ}

\author{
КучИН Николай Николаевич, Нижегородский государственный инженерно-экономический \\ университет \\ МАНСУРОВ Александр Петрович, ИПТД филиал ГБОУ ВО НГИЭУ \\ жУжин Максим Сергеевич, Нижегородский государственный инженерно-экономический \\ университет
}

ЛОМАЧЕНКО Оксана Александровна, Нижегородский государственный

инженерно-экономический университет

В статье представлен обзор операций технологического процесса заготовки сенажа в рулоне, упакованного в пленку, а также технические средства, с помощъю которых данные операции выполняются. В результате выявлены достоинства и недостатки технологии заготовки сенажа в рулон, упакованного в пленку, и предложены пути их решения.

Введение. Вопрос создания качественной кормовой базы, которая удовлетворяла бы потребности животных в питательных веществах, а также способствовала достижению высокой продуктивности, является актуальным. Важность данной проблемы отражена на высшем уровне - в Указе Президента РФ №350 от 21.07.2016 г. «О мерах по реализации государственной научно-технической политики в интересах развития сельского хозяйства» на период до 2026 года [11], в котором поставлена задача производства высококачественных кормов за счет внедрения современных конкурентоспособных технологий. При традиционных технологиях консервирования сенажа происходят значительные потери питательных веществ. На данный момент времени применяются разные технологии и способы хранения и заготовки сенажа.
Технология заготовки сенажа в рулоны, упакованного в пленку, является одной из конкурентоспособных как в России, так и зарубежном. Суть данной технологии в том, что скошенные травы быстро и равномерно провяливаются, плотно прессуются и надежно упаковываются в герметичную пленку, что позволяет получить качественный корм с минимальными потерями выращенного урожая.

Затраты на корма в структуре себестоимости продуктов животноводства составляют более $50 \%$, поэтому в условиях современной рыночной экономики производство и использование высококачественных кормов обладают приоритетным и стратегическим значением.

При заготовке сенажа в рулонах, упакованного в пленку, получается высококачественный корм, использование которого оправдано как 


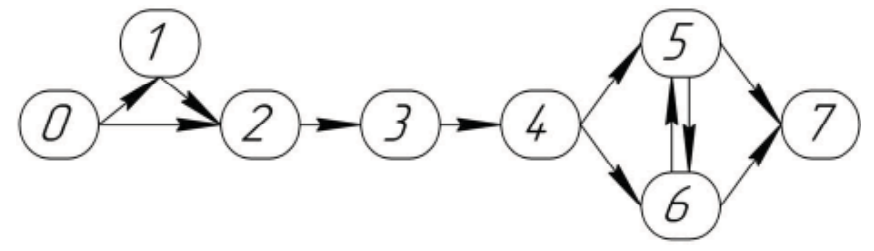

Рис. 1. Схема технологического процесса заготовки сенажа в рулонах: упакованных в пленку

о - травостой; 1 - скашивание; 2 - сгребание;

3 -ворошение; 4 - прессование; 5 - упаковка; 6- транспортирование; 7 - хранение

физиологически, так и экономически, однако для использования данной технологии требуется ее адаптация к конкретным производственными условиям.

Цель исследования - провести анализ технологического процесса заготовки сенажа в рулонах, упакованного в пленку, выявить достоинства и недостатки данной технологии.

Методика исследований. Проблема сохранения сенажа является важным практическим аспектом для сельскохозяйственных организаций. Заготовка и хранение корма - два важнейших фактора, влияющих на качество сенажа. При кормлении животных сенажом в рулонах, упакованным в пленку, увеличивается их продуктивность, так как в таком сенаже больше питательных веществ, чем, например, в сенаже при традиционном способе заготовки. Однако есть вероятность порчи упаковки, вследствие чего корм будет испорчен. Для повышения эффективности процесса заготовки сенажа в упаковке необходимо внесение консервантов. Эта мера направлена на улучшение качества корма и предотвращение вторичной ферментации, которая происходит из-за попадания воздуха в упаковку.

Рассмотрим преимущества данной технологии в сравнении с траншейным и башенным типами хранения:

полный процесс заготовки завершается за несколько часов;

для хранения сенажа в пленке подходят уличные условия;

качество корма отличное, несравнимо с кормами, заготовленными другими способами, что в результате повышает продуктивность животных;

потери питательных веществ практически отсутствуют;

производительность труда повышается в два раза. В результате окупаемость вложенных средств составляет не более 3 лет [1].

В зависимости от климатических условий региона хозяйства, учитывая свою специфику, определяют совокупность операций при заготовке корма. В процессе заготовки сенажа в рулоне, упакованного в пленку могут быть разные операции, обязательными из них являются скашивание, сгребание, ворошение, подбор, прессование, транспортирование, упаковка рулонов, укладка их на хранение. [1].
В хозяйствах России используются различные варианты технологии заготовки сенажа в рулонах [1]. Проведенный анализ показывает, что любой из этих вариантов осуществляется последовательным выполнением семи основных этапов (рис. 1).

На рис. 1 представлена схема технологического процесса заготовки сенажа в рулонах, упакованного в пленку. Видно, что технологический процесс может протекать несколькими вариантами. Применительно к конкретным хозяйственным условиям любой из вариантов может быть эффективнее другого.

Рассмотрим подробно каждую операцию при заготовке сенажа в рулон, упакованного в пленку согласно рис. 1.

Результаты исследований. Технология приготовления сенажа включает в себя следующие операции:

0. Травостой - в основном используют многолетние бобовые травы, являющиеся источником дешевого растительного белка. К наиболее используемым в кормопроизводстве многолетним бобовым травам относятся: клевер, люцерна, эспарцет, донник, козлятник.

1. Скашивание - происходит у бобовых в фазе бутонизации, у злаковых в фазе выметывания. Скашивание трав может быть разнообразным: в прокос или валок, вспушивание трав, сгребание трав. Скашивание трав может выполняться косилками, оборудованными ротационным и сегментно-пальцевым режущим аппаратом.

За рубежом для обеспечения качественного скашивания трав используют ротационные косилки на высоких поступательных скоростях для полеглых и перепутанных травостоев. По мнению большинства экспертов такие косилки, по сравнению с сегментно-пальцевыми с возвратно-поступательным движением ножей, на $30 \%$ производительней [3]. Ротационные косилки «Kem-per», «Fella», «Kuhn», «Vicon-Kverneland», «Stoll», «Claas», «Fisher», «Krone», «Бобруйскагромаш», «Клевер» пользуются наибольшей популярностью.

В России выпускают ротационные косилки следующих моделей: дисковая косилка КРН-2,1 шириной захвата 2,1 м; ротационные дисковые косилки КРН-1,5; КРН-1,9; КР-2,1А; КРН-2,4; КР-2,4 шириной захвата от 1,5 м до 2,4 м; косилки Strige ЖТT-2,1, ЖТТ-2,4, ЖТТ-2,8 шириной захвата 2,1...2,8 м. Следует отметить, что использование ротационных косилок в российских условиях не всегда целесообразно. При низкой урожайности сенокосов, а также на небольших полях широко используются косилки с сегментно-пальцевым ножевым аппаратом. Наиболее распространенные модели отечественных сегментно-пальцевых косилок: однобрусные навесные скоростные косилки КС-Ф-2,1 и КСГ-Ф-2,1 шириной захвата 2,1 
м, двухбрусные полунавесные косилки КД-Ф-4 и КДП-4 шириной захвата 4 м, трехбрусные прицепные косилки КП-Ф-6 и КТП-6 шириной захвата 6 м. Сравнивая ротационные косилки при данных условиях с сегментно-пальцевыми косилками, следует отметить, что последние гораздо дешевле в использовании $[2,5,8]$.

2. Сгребание. После как трава стала влажностью 50-70 \%, с помощью граблей и ворошилок формируются валки, плотность которых составляет 7 кг на погонный метр. Рассмотрим классификацию граблей и ворошилок для формирования валков. По типу рабочих органов различают ротационные, барабанные, колесно-пальцевые и конвейерные. По способу агрегатирования прицепные, полуприцепные и навесные. Самые популярные в мировой практике грабли - ротационные с рабочими элементами в форме пружинных зубьев, закрепленных на управляемых штангах, такие грабли ускоряют сушку за счет чистого сгребания и равномерного, вспушенного валка, что позволяет получить высококачественный корм $[4,6]$.

Колесно-пальцевые грабли итальянских производителей - фирм «Tonutti» (Milenium, Raptor, RCS) и «Sitrex» (Magnum, Sitrex RP, Sitrex HDY16) - незначительно уступают по технологическим свойствам роторным граблям, но имеют гораздо меньшую цену. По лицензии фирмы «Sitrex» они производятся в России на заводе «Навигатор-НМ» в г. Пермь под марками Н-90 и Н-94.

За рубежом производят как специальные машины, так и универсальные, которые выполняют функцию ворошения и сгребания травы. Производят такие машины следующие фирмы: «Claas», «Kuhn», «Stoll», «Krone» «Fella», «Pottinger» и др.

В России в настоящее время производят только универсальные машины: однороторные грабли-ворошилки ГР-3,6 шириной захвата 3,6 м (Людиновский машиностроительный завод), двухроторные ГВР-6 («Белагромаш» и «Бежец-ксельмаш») и ГВД-6 шириной захвата 6 м (Людиновский машиностроительный завод и Нефтекамский автомобильный завод).

3. Ворошение (вспушивание) массы. Целью ворошения массы является подсушить траву в короткий промежуток времени (4-6 ч) до влажности 50-70 \%. Ворошение травы происходит сразу, после скашивания.

4. Прессование сенажной массы. Для прессования используются косилки-плющилки, которые скашивают траву, расплющивают, раздавливают стебли, за счет чего ускоряется влагоотдача. Начинают прессование после того, как влажность массы достигает 50-70 \%. Подбор валков с одновременным прессованием начинают при влажности массы 55-60 \%.
Косилка-плющилка КПРН-3,0 с рабочим захватом 3,0 м; косилка-плющилка КП-2,4В шириной захвата 2,4 м; прицепная косилка-плющилка КРП-302 “Berkut” шириной захвата 3,2 м, это косилки отечественного производства. Ротационные косилки, оборудуемые кондиционерами динамического действия, более компактны, чем вальцовые аппараты. Машиностроительные фирмы: “Claas”, “Krone”, “Case”, “Kuhn”, “John Deer”, “Kverneland Group”, “Бобруйскагромаш” и др. выпускают такие косилки за рубежом. В России такие машины выпускаются на предприятии «Клевер». Российские пресс-подборщики, которые могут обеспечить нужную плотность (свыше 350 кг $/ \mathrm{M}^{3}$ ) для заготовки сенажа в рулон, выпускают в г. Пермь. Работают они по лицензии итальянской фирмы «Wolagri» и выпускаются на двух предприятиях: «Навигатор-НМ» - RB 15/2000 и «Краснокамский РМЗ» - под марками R10/155 Super, R12/155 Super, R12/2000 Super [7, 10].

5. Упаковка рулонов в пленку. После транспортирования рулонов к месту упаковки, не позднее 3 ч после формирования рулона, проводят непосредственную упаковку. По мнению большинства авторов, занимающихся изучением сенажа в рулонах, упакованного в пленку, и инженеров сельскохозяйственных организаций, использующих данную технологию, минимальное количество слоев пленки 6 [13]. Нормативным документом данный показатель не регламентирован, но для разных технических средств свои рекомендации фирма-производитель указывает в руководстве по эксплуатации.

Одну из важнейших ролей в заготовке такого корма играют обмотчики рулонов. Чтобы травяная масса не нагревалась, после прессования рулоны необходимо обмотать пленкой. Устройства для упаковки рулонов в пленку производят многие фирмы: «Anderson Group», «Wolagri», «Kverneland Group», «Class», «John Deere», «New Holland», «Krone», “Kuhn”, “Sipma”, “Бобруйскагромаш”, “Краснокамский РМЗ”, “НавигаторНМ” и другие.

На российском рынке большой популярностью пользуется машиностроительная фирма «Sipma» (Польша): обмотчик с самозагрузкой Z-557, прицепной самозагружающийся обмотчик OS 7535 MAJA (рис. 2), навесные обмотчики Z-274 и Z-274/1 и т.Д.

6. Транспортирование. В течение 2 ч, не позднее этого, после прессования рулоны перевозят к месту упаковки. Очень важна слаженная работа по времени пресс-подборщиков, погрузчиков, транспортировщиков и упаковщиков рулонов, а также выполнение технологических требований для обеспечения качественного корма.

Данные задачи выполняются транспортными средствами отечественного производства. По лицензии канадской фирмы «Anderson Group» 


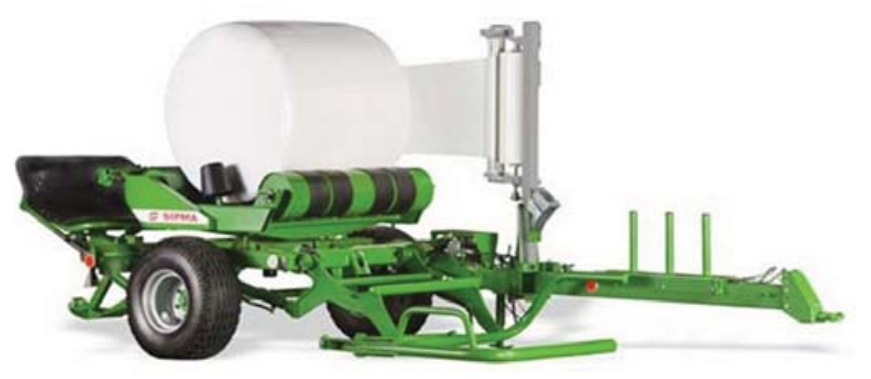

Рис. 2. Индивидуальный обмотчик рулонов OS 7535 МАJА

предприятие «Навигатор - НM» производит линейку самозагружающихся транспортировщиков рулонов TRB различных марок, которые отличаются друг от друга грузоподъемностью и вместительностью. Также для перевозки рулонов используются прицеп тракторный самосвальный 2ПТС-14 производства ОАО «Лидагропроммаш» (Беларусь) и прямобортные самосвалы КамАЗ45143 и ГАЗ-САЗ-3507.

7. Хранение. Для хранения такого сенажа достаточно иметь ровную поверхность открытого типа. Производители пленки дают гарантию хранения такого корма 2 года, что, в принципе, и подтверждается на практике. Важно сразу после упаковки уложить рулоны на постоянное место хранения, иначе через 48 ч снижается эластичность пленки.

На сегодняшний день сенаж - это практически единственный корм, состав которого даже в зимний период мало отличается от зеленой массы. Рулоны сенажа режут на нужные размеры и осуществляют раздачу непосредственно в кормушки. Предприятия, где раздача корма автоматизирована, используют резчики-кормораздатчики или посредством кормосмесителей.

Выделим особенности данной технологии, которые определяют ее успех:

весь цикл заготовки корма от скошенной травы до упакованного в пленку рулона на складе протекает в один день;

за счет заготовки сенажа в упаковке из целых растений, КРС при кормлении обеспечивается полноценной жвачкой как в летний период;

за счет технологических особенностей заготовки корма по данной технологии, которая протекает в течение нескольких часов, исключается риск порчи корма под воздействием погодных условий;

кормление животных даже в зимний период осуществляется кормом, качественные признаки которого максимально близки к свежескошенной траве, если сравнить с кормом из траншеи, то после вскрытия его качество снижается через 3 дня почти на $50 \%$;

В зимний период, например, в Нижегородской области сенаж в рулоне, упакованный в пленку, с влажностью 40-55 \% не промерзает даже в сильные морозы. Корм с большей влажностью может промерзать по окружности вследствие конденсата из-за перепада дневной и ночной температуры воздуха. Следует отметить, что качество корма в этом случае не ухудшается.

Однако существуют риски, которые можно отнести к недостаткам данной технологии. Пленка легко может быть испорчена грызунами, птицами или иным способом. В результате попадания в корм воздуха происходит вторичная ферментация, характеризующаяся развитием гнилостных бактерий и плесени. Для их устранения есть потребность во внесении различных форм химических или биологических препаратов, позволяющих обеспечить надежную сохранность такого корма.

Заключение. В результате вышеизложенного, следует отметить, что технология заготовки герметично упакованного сенажа в рулонах обеспечивает высокую сохранность всех питательных веществ корма. Однако герметизация корма пленочным материалом содержит риск порчи сенажа при повреждении упаковки. Внесение консервантов позволяет на некоторое время предотвращать аэробную порчу. Однако существует проблема точного дозирования и равномерного распределения эффективных и дешевых порошкообразных препаратов в кормовой массе. Поэтому разработка дозирующего устройства для внесения таких консервантов является актуальной и своевременной.

\section{СПИСОК ЛИТЕРАТУРЫ}

1. Бондарев В.А. Теоретическое обоснование и разработка способов повышения эффективности технологий заготовки и хранения силоса и сенажа: автореф. дис....д-ра с.-х. наук: 06.02 .02 / В.А. Бондарев. M., 1989. - 32c.

2. Мишуров А.В., Абрамян А.С. Динамика провяливания трав и полевые потери сухого вещества при различных технологических операциях // Сб. науч. трудов Тверской ГСХА. - Тверь, 2008. - С. 161-164.

3. Орлянская И.А. Повышение эффективности процесса заготовки сенажа в рулонах, упакованных в пленку: дис. ... канд. техн. наук. - М., 2018. - С. 22-26.

4. Орлянская И.А., Орлянский А.В. Петенев, А.Н. К выбору граблей при заготовке кормов из трав // Актуальные проблемы научно-технического прогресса в АПК: сб. науч. тр. - Ставрополь, 2013. - С. 308.

5. Особов В.И. Механическая технология кормов. - М.: Колос, 2009. - 344 с.

6. Особов В.И. Комплекс машин для заготовки сенажа // Животноводство России. - 2008. - № 6. C. 64-65.

7. Особов В.И. Комплекс машин для заготовки сенажа // Животноводство России. - 2008. - № 6. C. 64-65.

8. Пиуновский И.И. Проблемы повышения качества кормов при заготовке их на сено и сенаж // Машинные технологии и техника для производства кормов, картофеля, сахарной и кормовой свеклы: сб. науч. тр.. - М.: ВИМ. -2001. - С. 97-103.

9. Патент РФ № 2615581, 16.02.2016 г. Жужин М.С., Кучин Н.Н. 
10. Соловъева Н.Ф. Современные рулонные прессподборщики // Техника и оборудование для села. 2001. - № 12. - С. 18-22.

11. Электронный ресурс: https://www.garant.ru/ products/ipo/prime/doc/71350102/ (дата обращения 06.01.2019).

12. Электронный ресурс: URL: http://www. schaumann.at/cps/schaumann-at/ds_doc/de-AT/ Dosiergeraete_Beschreibung.pdf (дата- обращения 01.02.2016).

13. Электронный ресурс: https://domaferma. com/oborudovanie/tehnologia-zagotovki-senaza-vrulonah.html (дата обращения 06.01.2019).

Кучин Николай Николаевич, $\partial-p$ c.- $\boldsymbol{x}$. наук, проф., научный сотрудник, ГБОУ ВО «Нижегородский государственный инженерно-экономический университет». Россия.
Мансуров Александр Петрович, $\partial-p$ c.- $x$. наук, проф., научный сотрудник, ИПТД филиал ГБОУ ВО «Нижегородский государственный инженерно-экономический университет». Россия.

Жужин Максим Сергеевич, канд. техн. наук, доцент кафедры «Электрификация и автоматизация», ГБОУ ВО «Нижегородский государственный инженерно-экономический университет». Россия.

Ломаченко Оксана Александровна, аспирант, ГБОУ ВО «Нижегородский государственный инженерно-экономический университет». Россия.

606360, Нижегородская область, г. Княгинино, ул. Октябрьская, 22 A.

Тел.: (83166) 4-15-50.

ключевые слова: сенаж; пленочная упаковка; заготовка кормов; сенаж в упаковке; технологчческий процесс заготовки сенажа.

\title{
PROBLEMS OF PRESERVATION OF THE SILAGE IN ROLLS, PACKED IN FILM
}

Kuchin Nikolay Nikolaevich, Doctor of Agricultural Sciences, Professor, Researcher, Nizhny Novgorod State University of Engineering and Economics. Russia.

Mansurov Alexander Petroich, Doctor of Agricultural Sciences, Professor, Researcher, Nizhny Novgorod State University of Engineering and Economics. Russia.

Zhuzhin Maxim Sergeevich, Candidate of Technical Sciences, Associate Professor of the chair "Electrification and Automation”, Nizhny Novgorod State University of Engineering and Economics. Russia.

Lomachenko Oksana Aleksandrovna, Post-graduate Student, Nizhny Novgorod State University of Engineering and

\section{Economics. Russia.}

Keywords: haylage; film packaging; fodder preparation; haylage in packaging; technological process of haylage preparation.

The article presents an overview of the operations of the technological process of preparing the seed in a roll packed in a film, as well as technical means by which these operations are performed. In the result, the advantages and disadvantages of the technology of haylage preparation in a roll packed in a film are revealed and ways of their solution are proposed.

\section{ИСПОЛЬЗОВАНИЕ ДВУХФАЗНОЙ СИСТЕМЫ СЖИЖЕННОГО УГЛЕВОДОРОДНОГО ГАЗА В СЕЛЬСКОМ ХОЗЯЙСТВЕ}

\author{
МАЛЫШЕВА Анна Александровна, Национальный исследовательский Московский \\ государственный строительный университет
}

В работе рассматривается изменение соотношения компонентов, при котором относительное содержание более легких углеводородов будет уменьшаться, а содержание более тяжелых увеличиваться. Для улучшения условий эксплуатации систем рассмотрены вопросы, связанные с расчетом двухфазной системы сжиженного углеводородного газа.

Введение. В ходе проектирования и эксплуатации установок, а также при транспортировке, хранении сжиженных углеводородных газов необходимо учитывать свойства отдельных компонентов и их смесей[4].

При интенсивном расходе газа температура жидкости будет резко падать, в результате чего при этом нарушится испарение и, как следствие, произойдет обмерзание сосуда. В связи с этим при эксплуатации баллонных установок очень важно учитывать вопросы безопасности, которые связаны с заполнением емкостей, изменением состава смеси углеводородных газов [1].
При транспортировании, хранении или регазификации углеводородные газы находятся в виде двухфазной системы, в состав которой входят жидкая и паровая фазы.

При эксплуатации следует учитывать такие свойства, как высокая плотность; медленная диффузия; низкая температура воспламенения; непостоянная теплота сгорания.

Основные свойства жидкой фазы включают в себя способность к сильному объемному сжатию и расширению, малую относительная плотность, охлаждающую способность при регазификации. 